\title{
CONF-9706/7--1 \\ EVALUATION OF A DOWNHOLE TILTMETER ARRAY FOR MONITORING HYDRAULIC FRACTURES
}

\author{
N. R. Warpinski ${ }^{1}$, P. T. Branagan ${ }^{2}$, B. P. Engler ${ }^{1}$, R. Wilmer ${ }^{2}$ and S. L Wolhart ${ }^{3}$ \\ ${ }^{1}$ Sandia National Laboratories, Albuquerque, NM, USA \\ ${ }^{2}$ Branagan \& Associates, Las Vegas, NV, USA \\ ${ }^{3}$ Gas Research Institute, Chicago, IL, USA

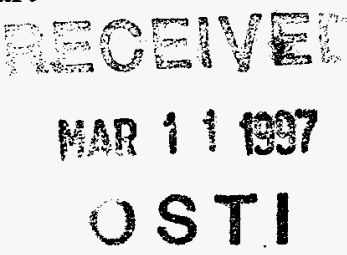

Sandia is a multiprogram laboratory operated by Sandia Corporation, a

ABSTRACT Lockheed Martin Company. for the United States Department of Energy under contract DE-AC04-94AL85000.

A series of hydraulic-fracture experiments using a downhole tiltmeter array, called an inclinometer array, was conducted at the Department of Energy (DOE)/Gas Research Institute (GRI) Multi-Site facility in Colorado. The inclinometer array was used to measure the deformation of the reservoir rock in response to hydraulic fracture opening and confirm microseismically measured results. In addition, the inclinometer array was found to be a useful tool for accurately measuring closure stress, measuring residual widths of both propped and unpropped fractures, estimating proppant distribution, and evaluating values of in situ moduli.

\section{KEYWORDS}

Hydraulic Fracturing, Tiltmeters, Inclinometers, Fracture Diagnostics, Microseisms, Microseismic Technique, Fracture Height, Closure Stress, Proppant Distribution, Fracture Width, In Situ Modulus, Stimulation, Reservoir Deformation.

\section{INTRODUCTION}

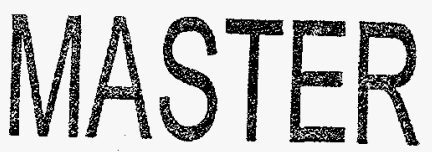

Hydraulic fracturing is now understood to be a complicated process (Gidley et al, 1989) governed by the injection parameters (fluid viscosity and density, injection rate), rock-mechanics properties (moduli, strength), in situ stress, and discontinuities (faults, fractures, bedding) within the reservoir medium. Because of the complexities introduced by common reservoir discontinuities, the fracturing process is poorly represented by standard models, and discrepancies between model results and production are often resolved by the introduction of any number of ad-hoc mechanisms that can be artificially adjusted to obtain the desired result (Warpinski et al, 1994).

As instrumentation technology and computer processing capabilities improve, however, it is slowly becoming possible to image hydraulic fractures using microseismic techniques introduced in the 1970's (Albright and Pearson, 1982; Hart et al, 1984). This advanced technology should provide sufficient data to better understand the fracturing mechanisms, validate models, and truly optimize fracture design. One final issue yet to be resolved, though, is the correlation between the "seismic" image of the fracture and the actual rock deformation (Warpinski, 1994). This paper describes the use of a downhole tiltmeter array, dubbed an inclinometer array to distinguish it from surface tiltmeters, to measure the actual rock deformation and provide a comparison with the microseismic results (Branagan et al, 1996). In addition, the inclinometer array has also provided other useful information on fracture behavior and reservoir properties, some of which is described here. 


\section{DISCLAIMER}

This report was prepared as an account of work sponsored by an agency of the United States Government. Neither the United States Government nor any agency thereof, nor any of their employees, make any warranty, express or implied, or assumes any legal liability or responsibility for the accuracy, completeness, or usefulness of any information, apparatus, product, or process disclosed, or represents that its use would not infringe privately owned rights. Reference herein to any specific commercial product, process, or service by trade name, trademark, manufacturer, or otherwise does not necessarily constitute or imply its endorsement, recommendation, or favoring by the United States Government or any agency thereof. The views and opinions of authors expressed herein do not necessar. ily state or reflect those of the United States Government or any agency thereof. 


\section{DISCLAMMER}

Portions of this document may be illegible in electronic image products. Images are produced from the best available original document. 
The inclinometer and microseismic data shown in this paper were all taken at the GRI/DOE M-Site experiment located in the Piceance basin of west-central Colorado near the town of Rifle (Peterson et al, 1996; Branagan et al, 1996; Warpinski et al, 1996). This site consists of several closely spaced wells, one of which has a 30-level tri-axial receiver array and a 6-level bi-axial inclinometer array grouted in place at depths from 1250-1500 $\mathrm{m}$ in Mesaverde strata. In addition, multi-level wireline tri-axial receivers are routinely run in other wells to monitor hydraulic fractures which have been conducted in 3 separate intervals. All these data are correlated with pressure and other injection parameters, as well as tracers and other diagnostics.

\section{MICROSEISMIC TECHNIQUE}

The microseismic technique, as applied here, involves the multi-level monitoring (Warpinski, 1994) of seismic disturbances triggered by the changes in stress and pressure associated with the hydraulic fracture using a tri-axial downhole receiver. By recording the compressional-wave and shear-wave arrivals and the particle motion of the compressional wave, the distance and direction to the origin point of the microseism can be measured. In practice, such a measurement is difficult in sedimentary environments with only a single receiver, and efforts have focused on developing multi-level arrays to accurately locate microseisms. Multi-level arrays have additional problems of telemetry rates and data processing requirements, but improvements in technology have now solved these aspects of the problem (Sleefe et al, 1995).

In a typical application, a microseism is detected on several receivers of the multi-level array, data are discriminated with an event detection scheme, relevant information are obtained, and the origin point is located assuming either a homogeneous formation or some more complicated layered environment. The microseisms usually form an ellipsoid around the fracture, mapping out the region in which stress and pressure have been changed sufficiently to allow rock discontinuities to undergo slippage. It is the slippage that induces the microseism, or microearthquake.

While microseisms can be mapped fairly accurately, the question has remained as to how well the microseismic image compares to the actual mechanical response. Since it is impossible to actually see the fracture, another possibility for verifying the microseismic image is to measure the rock deformation and show the comparison between deformation and seismic results. Such a deformation measurement would be difficult to achieve with any of the common stress or strain measurement devices, but the tiltmeter provides both the sensitivity and the emplacement capability for obtaining such measurements.

\section{INCLINOMETER ARRAY}

Tiltmeters have successfully been employed for years as a surface monitoring technique for hydraulic fractures (Davis, 1983; Palmer, 1990; Wright and Conant, 1995). These devices provide reliable information on fracture azimuth and, occasionally, can also provide other useful information about fracturing characteristics. This study employs tiltmeters in a new mode which is proving useful for extracting other valuable information about fracture dimensions and fracture mechanisms.

The method of deployment is a vertical array of tiltmeters cemented in place in an offset well, at a depth directly across from the hydraulic fracture (Branagan et al, 1996). Being in a nearby offset well, the inclination amplitudes are several orders of magnitude greater than would be detected at the surface. Furthermore, since the inclination is a gradient of the strain, all of the crack models in the literature can be reinterpreted in terms of the inclination and exactly the same information can be obtained as if stress or strain measurements were made. In particular, a linear array of inclinometers in a vertical well adjacent to a hydraulic fracture provides highly sensitive data on the fracture height and width and second order sensitivity on the length. These results can be used to validate the microseismic data. 
In addition to the height confirmation, however, the inclinometers also provided several other important pieces of information, such as a value of the minimum in situ stress based on the actual measurement of fracture opening, a measure of the fracture width during the treatment, a measure of residual width after the treatments, and a validation of the correct in situ modulus for hydraulic fracture modeling.

\section{MODELING INCLINOMETER DEFORMATION RESULTS}

In order to interpret the inclinometer data, it is necessary to reformulate typical stress-strain equations in terms of the gradient of the strain (Warpinski, 1994). There are several analytic solutions that can be applied to inclinometers directly, including Sneddon's (1946) formulations for 2-D and radial cracks, Green and Sneddon's (1949) solution for a flat elliptical crack, and England and Green's (1963) solution for a 2-D crack with a variable pressure distribution which can also be used to solve the case of a variable stress distribution in the reservoir. Since there is not enough space here to give details for each, only the simplest case of a $2 \mathrm{D}$ crack is shown.

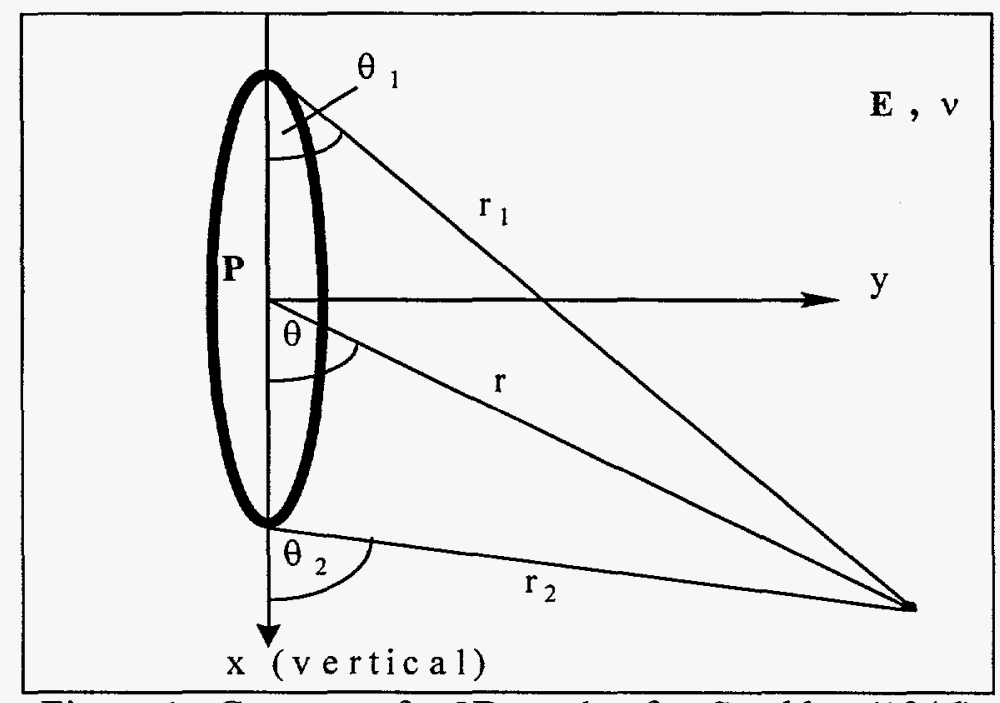

Figure 1: Geometry for 2D crack, after Sneddon (1946)

Sneddon (1946) gives a formulation for an infinite 2-D vertical crack in terms of radial distances and angles from the center and tips of a crack to any external point. The geometry of this example is shown in Figure 1. Formulations for the inclination are straightforward and are given in terms of the pressure, P, Poisson's ratio, $v$, Young's modulus, E, and the geometry parameters as

$$
\frac{\partial u_{y}}{\partial x}=\frac{2(1+v) P}{E}\left[(1-v) \frac{r}{\sqrt{r_{1} r_{2}}} \sin \left\{\theta-\frac{1}{2}\left(\theta_{1}+\theta_{2}\right)\right\}+\frac{r \sin \theta}{2 c}\left(\frac{c^{2}}{r_{1} r_{2}}\right)^{1.5} \cos \left\{\frac{3}{2}\left(\theta_{1}+\theta_{2}\right)\right\}\right]
$$

and

$$
\frac{\partial u_{z}}{\partial x}=0,
$$

where $u_{y}$ and $u_{z}$ are the strains normal to a vertical crack and out of the plane of the crack, respectively, and $x$ is the vertical axis.

\section{COMPARISON OF MICROSEISMIC AND INCLINOMETER RESULTS}

The primary reason for emplacing the inclinometer array was to verify the seismic diagnostic accuracy. Figure 2 shows the test geometry for a series of experiments that was conducted at M-Site. The lateral 
spacing between the monitor well and the fracture well was approximately $100 \mathrm{~m}$, while the spacing between the wireline well and the fracture well was about $64 \mathrm{~m}$. For a minifrac designated $6 \mathrm{~B}$ (one of 7 tests in the B sandstone), a linear gel minifrac consisting of $64 \mathrm{~m}^{3}$ of fluid pumped at $3.5 \mathrm{~m} / \mathrm{min}, 30$ levels of tri-axial seismic receivers in the monitor well were active, as well as a 5-level array in the offset wireline well. In addition, the 6 bi-axial tiltmeters ( 3 around the $B$ sandstone, 3 around the $C$ sandstone) were also monitoring formation deformation during and after the fracture treatment.

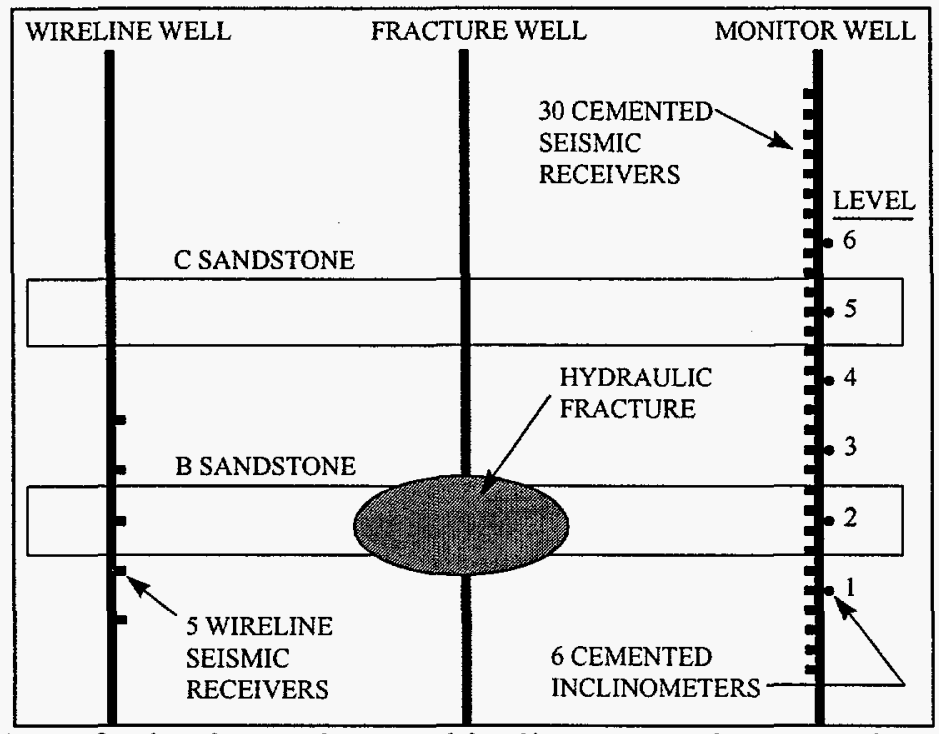

Figure 2: Configuration of seismic receives and inclinometers for B-sandstone linear gel minifrac.

Figure 3 shows a side view image of the microseisms detected during a linear-gel minifrac from receivers in two wells (different symbols for data from each well). This image indicates that the microseismic height is on the order of $23 \mathrm{~m}$, depending on how the three outlier points (one above, two below) are treated. The fracture is asymmetric, with the east (right-side) wing length being $120-135 \mathrm{~m}$ and the west (left-side) wing being only $80-90 \mathrm{~m}$. Although it can not be shown in this paper, much additional information can be extracted by viewing the development of the microseisms with time. Growth patterns show that the fractures initially are confined within the sandstone interval and quickly achieve significant length. However, once a certain pressure level is reached and height growth begins, the length growth slows markedly.

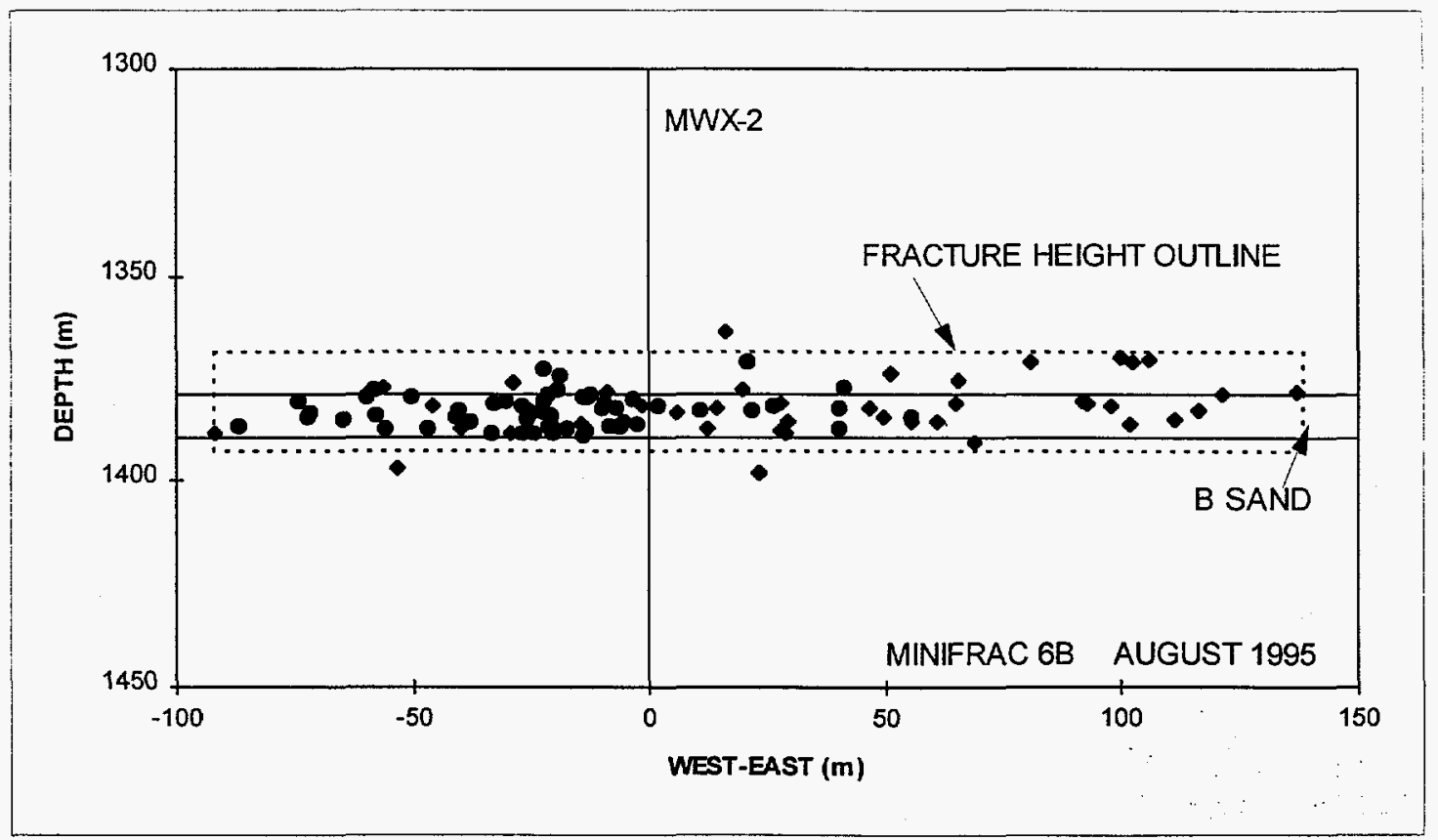

Figure 3: Microseismic image of a linear-gel minifrac in B sandstone at M-Site 
To confirm these types of results, inclinometer data were taken during the same hydraulic-fracture tests. These data were inversely modeled to extract the geometry of the fracture causing the deformation. Figure 4 shows an example of the inclinometer data taken in a direction normal to the fracture as a function of time. In these data, the rapid response of the tiltmeters to fracture opening can be seen. The large amplitudes of the inclination for a downhole array is apparent, especially when compared to nanoradian or 10's of nanoradian response for typical surface tiltmeters. The closure process also is well monitored by these instruments, allowing residual widths and other parameters to be estimated.

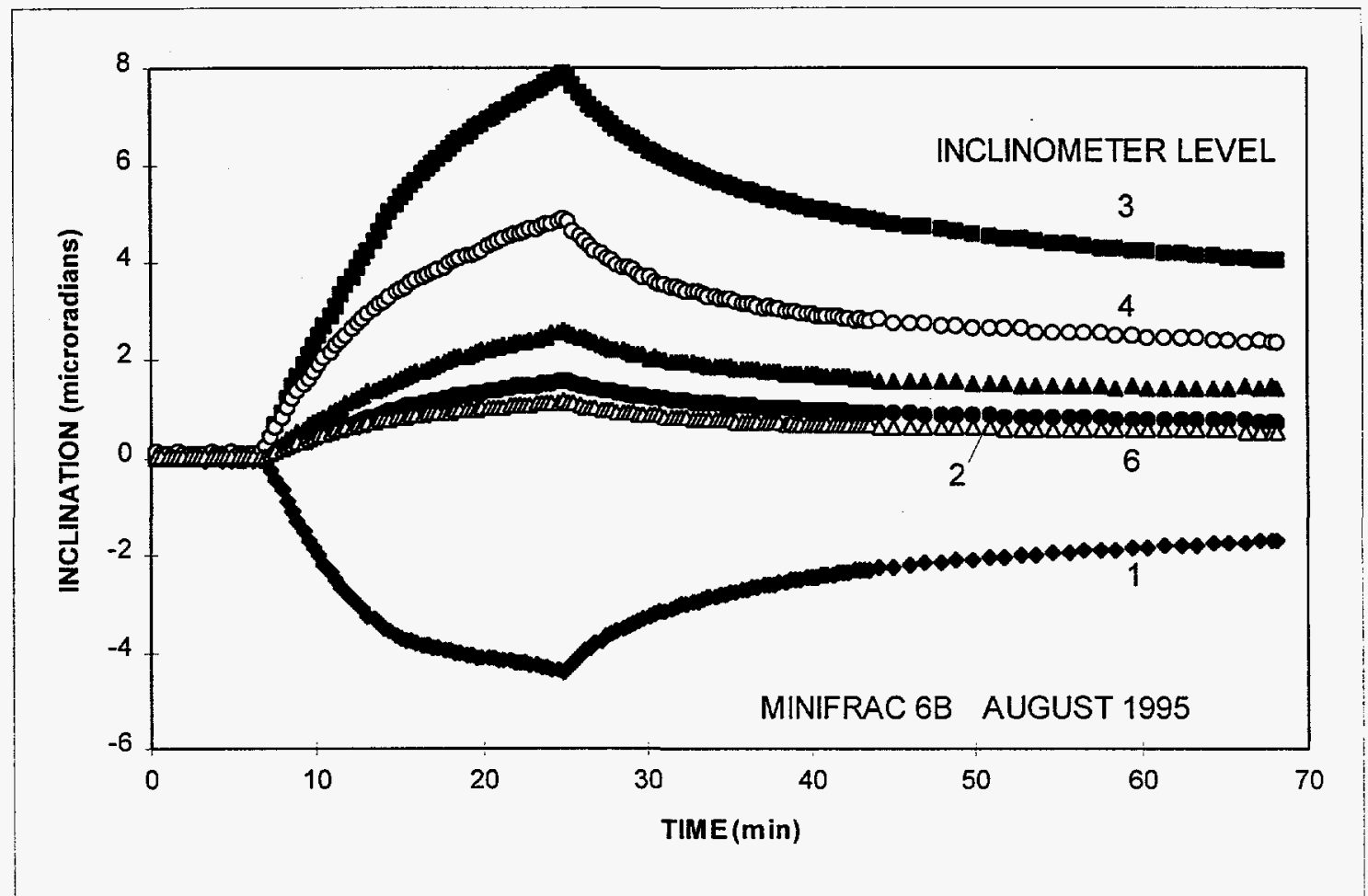

Figure 4: Inclinometer data as function of time for linear-gel minifrac in B sandstone at M-Site

The maximum inclinometer data (taken at the end of pumping) as a function of depth are shown in Figure 5 with comparison to several models. The inverse task is to find fracture height and length parameters that provide the best possible match of the measured minifrac data. All other parameters, including formation moduli and stress, injection pressure, and distances and orientation from the fracture are presumably known. Shown in Figure 5 are two cases for an infinite 2-D crack solution (heights of 18.3 and $27.4 \mathrm{~m}$ ) that bracket the response of the actual data. The $27.4 \mathrm{~m}$ height fits the maximum amplitude better, but the $18.3 \mathrm{~m}$ height fits the fall off of the top inclinometers. Also shown for comparison is a 3-D elliptic crack model which has a length of $122 \mathrm{~m}$ (approximately the seismic length on the right wing). This model shows the effect of crack length on the magnitude of the inclinations. Finally, a finite-element model which includes layering (moduli and stresses) and a crack length of $122 \mathrm{~m}$ is shown. This model clearly provides the best match and shows that the difficulty in matching the overall data with the analytic models is due to the modulus differences of the various layers in the reservoir. The best match value of about $20.4 \mathrm{~m} \pm 2 \mathrm{~m}$ is in good agreement with the seismic height of $23 \mathrm{~m}$.

A comparison of the seismic height to the inclinometer heights (all taken from finite-element models) for the five tests in which there are good data for both is shown in Table 1. In general, the inclinometer heights are slightly less than the seismic heights. The final fracture, 7B, shows the same heights for the imaged and modeled geometries because the seismic height distribution was too complex to compare with a constant height model. Instead, the seismic geometry (which included a large-height section $(41.9 \mathrm{~m})$ near the wellbore and a reduced-height section $(24.4 \mathrm{~m}$ ) at the extremity) was used in the finite-element model and gave excellent agreement. The small discrepancy seen in fractures $3 \mathrm{~B}-6 \mathrm{~B}$ could be due to inaccurate moduli and stress values for the various layers or could be due to the microseisms occurring out ahead of the 
- crack tip caused by increased shear stresses in the tip vicinity. Nevertheless, the agreement between seismic and inclination results is excellent and clearly validates the seismic heights.

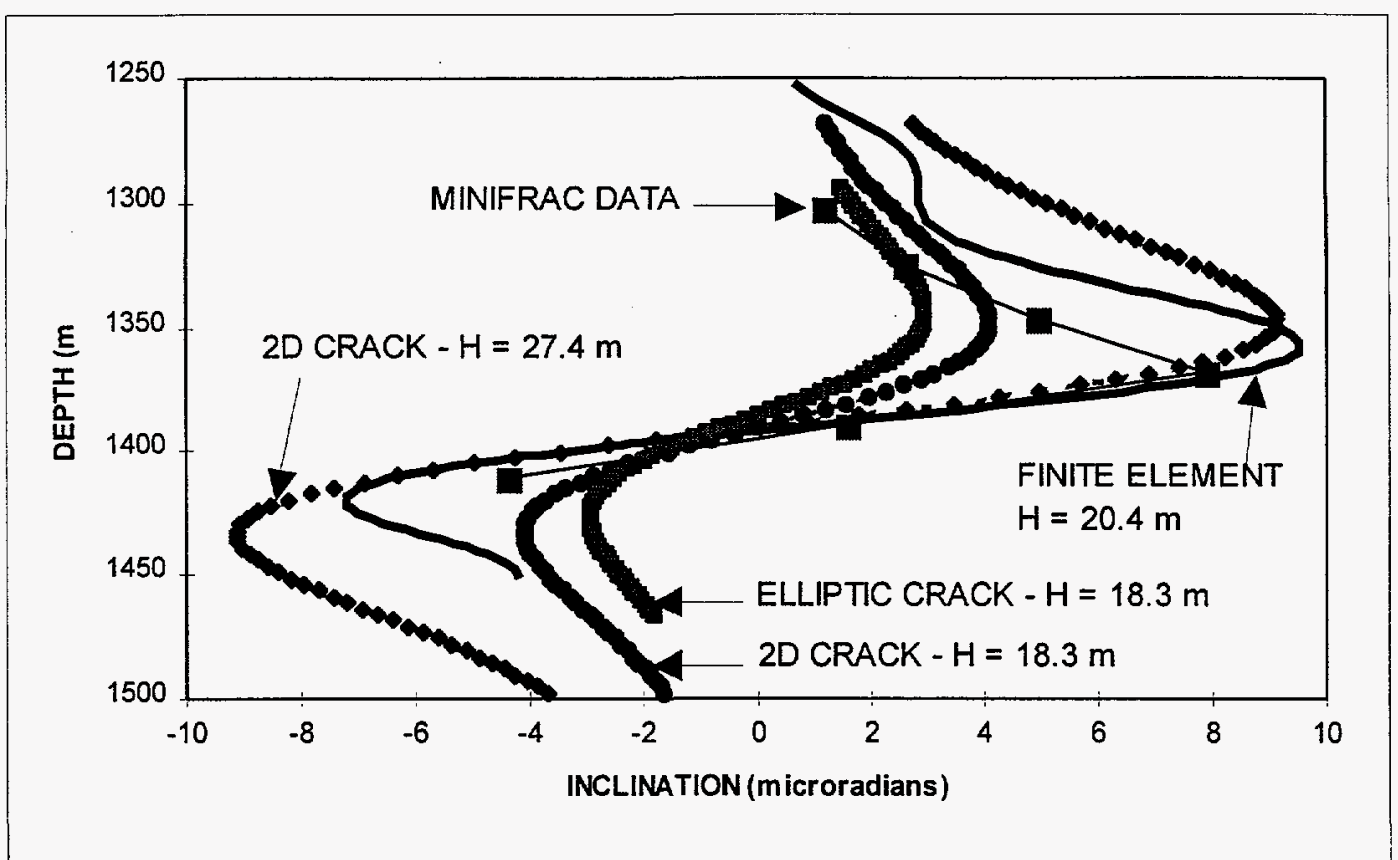

Figure 5: Inclinometer data as function of depth with model comparisons for linear-gel minifrac

TABLE 1

COMPARISON OF HEIGHTS USING SEISMIC AND INCLINATION RESULTS

\begin{tabular}{|c||c|c|c|}
\hline Test & Fluid & Seismic Width & Inclinometer Width \\
\hline \hline $3 \mathrm{~b}$ & Water & $16.8 \mathrm{M}$ & $15.8 \mathrm{M}$ \\
\hline $4 \mathrm{~b}$ & Water & $16.8 \mathrm{M}$ & $15.8 \mathrm{M}$ \\
\hline $5 \mathrm{~b}$ & Linear Gel & $24.4 \mathrm{M}$ & $20.4 \mathrm{M}$ \\
\hline 6b & Linear Gel & $22.9 \mathrm{M}$ & $20.4 \mathrm{M}$ \\
\hline $7 \mathrm{~b}$ & Cross-Linked Gel & $41.1 / 24.4 \mathrm{M}$ & $41.1 / 24.4 \mathrm{M}$ \\
\hline
\end{tabular}

\section{MEASUREMENT OF CLOSURE STRESS}

One of the most important parameters for hydraulic fracturing analysis and modeling is the closure stress, defined as the baseline stress of the reservoir interval which is being fractured. Since all pressure measurements include the closure stress plus the net fracturing pressure, this parameter must be accurately measured to obtain realistic model matches. Unfortunately, there is much disagreement in the literature about how the closure stress should be measured and how to interpret closure-stress tests. The application of downhole inclinometers has helped provide new information on fracture opening and closure and our ability to make good closure stress measurements.

Probably the most surprising aspect of all of the tests conducted at M-Site, whether they were water, lineargel, or cross-linked-gel injections, was the complete lack of any indication of mechanical closure in the inclinometer results. As seen in Figure 4, the fracture closure process is a smooth, continuous one which often leaves residual inclinations of $20-30 \%$ of the maximum recorded value at any station. This residual tilt is probably due to residual width in the crack, poro-elastic expansion due to increased pore pressure, and slight shifting of the formation in response to the hydraulic fracture. Microseisms, which are shear slippages, provide proof that some re-adjustment of the formation is occurring. The smooth decrease in inclination suggests that the entire process is a very continuous one where no point can be construed to be the closure of 
the crack. Thus, the difficulty in choosing closure from a hydraulic-fracture stress test is to be expected since there is no closure point in the actual rock deformation.

Fortunately, the inclinometers can be used to determine closure stress upon reopening of a fracture. Figure 6 shows the beginning of an injection in the B sandstone using water pumped at a low rate $(0.2 \mathrm{~m} / \mathrm{min})$ to measure the point at which the crack begins to dilate. In this case, the crack response, which begins at about 18.5 minutes, can be compared to the downhole pressure to obtain the closure stress, which for this sandstone is approximately $21 \mathrm{MPa}$. This technique was found to be successful in the $\mathrm{C}$ sandstone as well.

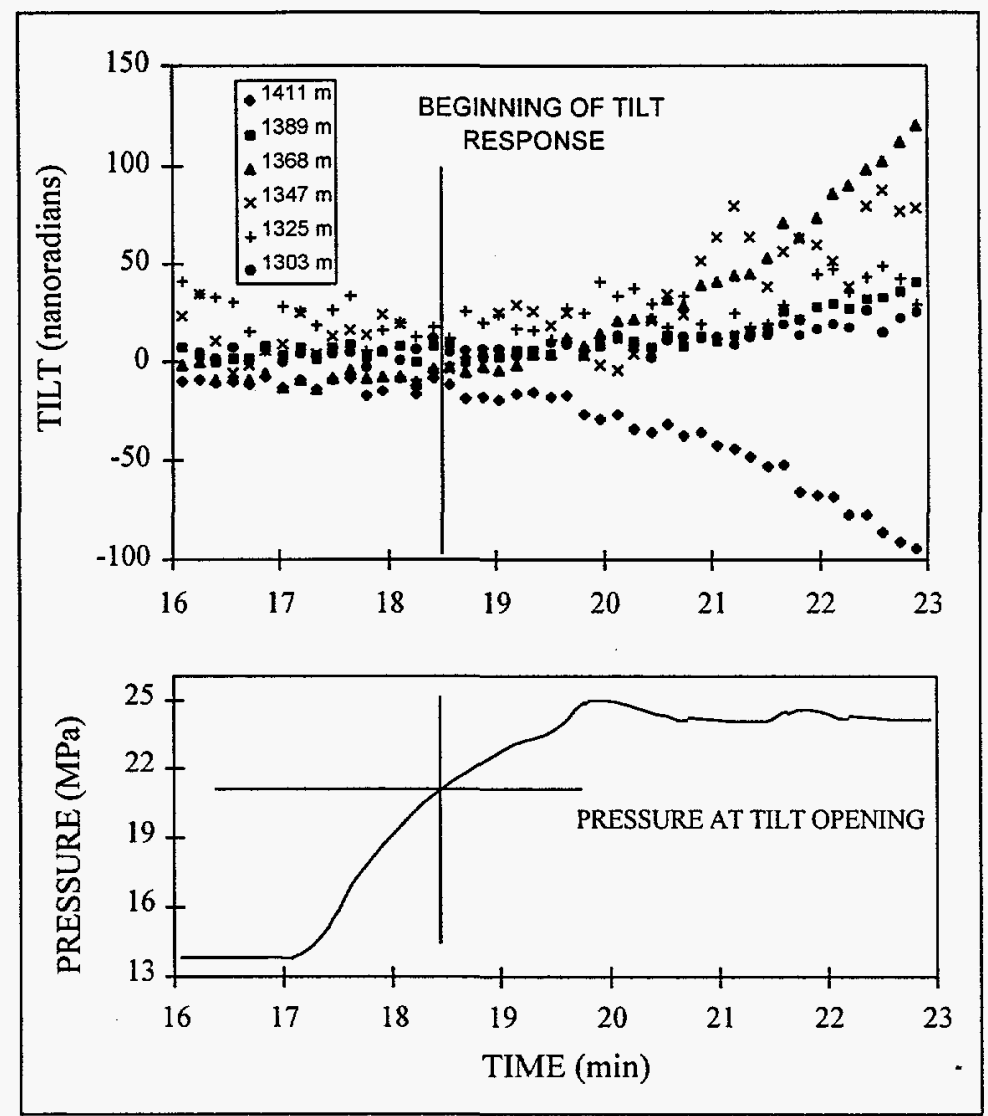

Figure 6: Inclinometer response showing crack opening and closure stress

The procedure for obtaining the closure stress requires that the formation be already fractured or broken down in order that a closed conductive crack be present. Otherwise, a large breakdown pressure may be required to start fracturing and no closure-stress measurement can be obtained. Secondly, the injection rate must be relatively slow so that fluid can penetrate into the fracture and begin to reduce stress on the fracture wall in a continuous manner. Otherwise, a reopening pressure is likely to be obtained, which again will make it impossible to determine the closure stress. When done correctly, the opening of the fracture is easily identifiable and the closure stress readily obtained. It is also worth noting that the closure stress measured in this manner is relatively close to that measured using small volume hydraulic fractures and finding a closure stress using square-root-of-time plots, graphical techniques, or other conventional means.

\section{RESIDUAL WIDTHS ASSOCIATED WITH UNPROPPED FRACTURES}

All of the tests at M-Site appear to leave a permanent or near-permanent residual deformation in the reservoir. Figure 7 shows the inclinations that were measured in the direction normal to the fracture on one of the inclinometers during a 40 day period during which four water injections were conducted between days 15 and 17. The first two injections were a very small breakdown (day 15) and a step-rate test (day 16) that resulted in maximum inclinations of only about $0.5 \mu$ radians above their baselines. Two additional injections, both conducted on day 17 , were considerably larger with respective injected volumes of 16 and 
$32 \mathrm{~m}^{3}$. These tests induced inclination responses of 4 and $4.5 \mu$ radians, respectively, relative to the previous injection. Interestingly, the four fracture treatments resulted in a permanent inclination offset of over 1 $\mu$ radian with most of this permanent offset occurring due to the last two injections. This permanent offset is most likely due to residual width $(\sim 0.5 \mathrm{~mm}$ for the observed residual deformation) since any poro-elastic component due to reservoir pressurization would have decayed within days. Relatively few microseisms were detected, indicated that the formation is undergoing little permanent redistribution during fracturing.

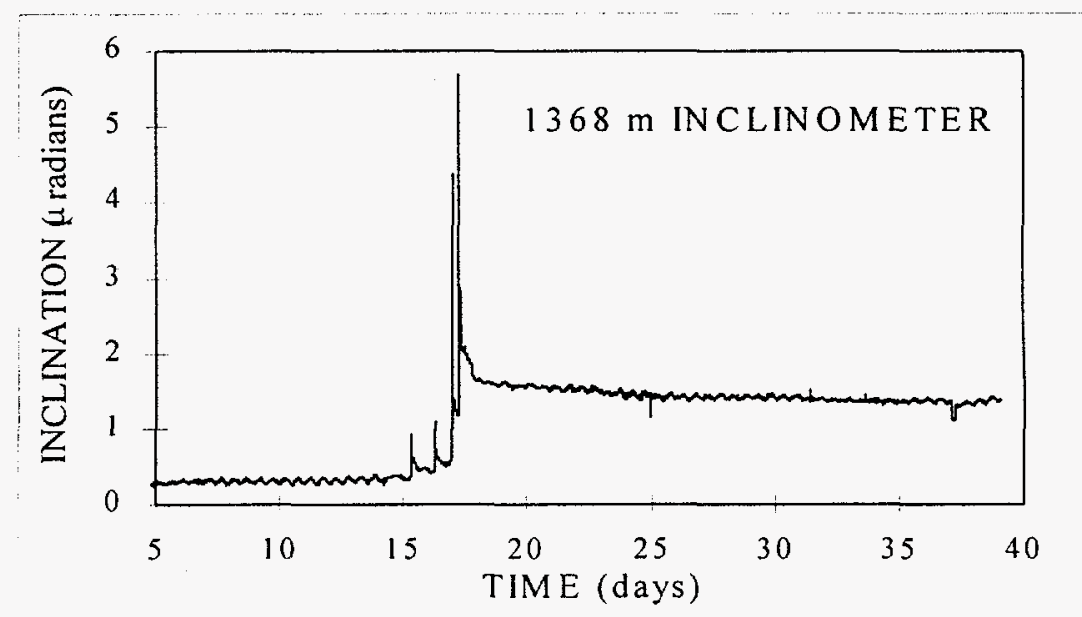

Figure 7: Residual inclinations measured at M-Site after four water injections

Such results have important implications for fracturing because they suggest that there are many cases where unpropped water fractures may leave sufficient conductivity to induce considerable stimulation. The amount of stimulation and the economics of such a process are, of course, very dependent on the permeability of the reservoir, as well as the residual fracture conductivity.

\section{PROPPANT PLACEMENT}

The measurement of residual widths also applies to propped fractures and can be used to measure the propped fracture width and the distribution of propping materials. Figure 8 shows a comparison of normalized inclination distributions at the end of pumping and after closure. The maximum inclination during pumping was $13.84 \mu$ radians and $5.40 \mu$ radians after closure with essentially the same distribution.

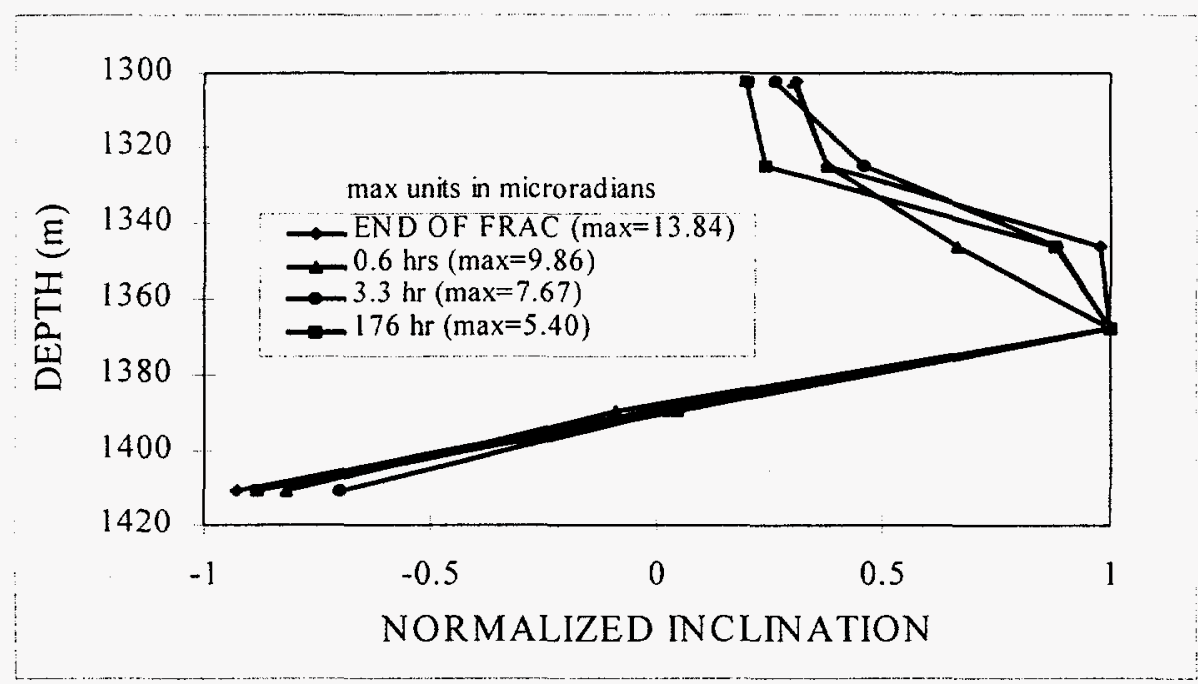

Figure 8: Comparison of inclination distributions during and after fracturing

Based on the finite element analyses, the maximum width at the wellbore was $1.1 \mathrm{~cm}$ at the end of pumping, so the maximum propped width is approximately $0.4 \mathrm{~cm}$ indicating a good sand pack in the reservoir. Furthermore, the similarity in distributions suggests that the fracture closed on the proppant before it settled 
to the bottom of the fracture, as is proposed in enhanced convection conditions. Had the sand settled to the bottom of the fracture, the proppant distribution would have changed radically with the peak shifting downward to indicate residual deformation near the bottom. These kinds of measurements can be valuable in assessing whether mechanisms such as convection actually play a significant role in normal fracturing treatments.

\section{IN SITU MODULI}

A serious concern for any modeling of the earth is the appropriate modulus to use in the analysis. Static lab measurements give accurate data for competent pieces of the rock material but do not address the effects of fractures and other discontinuities on the modulus for a reservoir as a whole. The finite-element modeling of the inclination results at $\mathrm{M}$-Site have provided some information in regard to the appropriate modulus value for tight rocks such as found in the Mesaverde formation at M-Site.

Initial modeling of the inclination data used laboratory quasi-static modulus values obtained on core at appropriate stress, at lab strain rates, and at room temperatures. These data (Branagan et al, 1996) provided the results given in this paper and were found to be quite acceptable for all modeling. Young's modulus and Poisson's ratio for the $\mathrm{B}$ sandstone were $31.5 \mathrm{GPa}$ and 0.2 , while for shales the values were typically $16.5 \mathrm{GPa}$ and 0.24 , respectively. An attempt was made, however, to try modeling with two different sets of moduli: (1) dynamic moduli which were about twice as large as the static values and are typical of the moduli obtained from sonic logs; and (2) reduced moduli which were decreased by a factor of 2 to account for natural fractures and other scale effects. It was quickly found the neither of these alternate moduli would allow for realistic modeling of the measured data. The dynamic modulus case required fractures that were extremely tall to match the amplitude, but then had a shift in the location of the peak. The reduced moduli calculations produced fractures that would not even propagate through half of the height of the sandstone to match the amplitudes of the measured inclinations. If it is assumed that the seismic heights are relatively accurate, then the moduli can not be changed more than about $10 \%$ or the modeled distribution will not match the measured data. These results confirm that in these tight rocks, laboratory quasi-static values measured at stress provide accurate moduli for deformation analyses.

\section{APPLICATION}

This series of tests shows that a downhole inclinometer array, while expensive to cement in the ground, can provide important fracture diagnostic capabilities. More appropriately, if such an array could be deployed in a wireline-run array, it could be installed in offset wells more than a kilometer away from the fracture and provide high quality data. Because of the large strains generated by the treatment and the nanoradian resolution of current tiltmeter devices, well spacing is not a significant restraint on the application of this technology. Furthermore, these results suggest that a downhole inclinometer array holds promise for monitoring many other geophysical processes and natural occurrences.

\section{CONCLUSIONS}

A series of experiments conducted at the GRI/DOE M-Site facility has shown that a downhole tiltmeter array, called an inclinometer array to distinguish it from surface tiltmeters, can provide high quality data to resolve many hydraulic fracture parameters and mechanisms. Based on the inclinometer results, it was found that the microseismic technique accurately measures the height of a hydraulic fracture in this reservoir environment, the main purpose for emplacing the array. Furthermore, the inclinometers have been found to be useful for accurately measuring the closure stress of the reservoir, obtaining fracture widths both during and after pumping, and estimating the distribution of proppant after closure. Finally, the inclinometer data 
have also been used to evaluate the correct moduli to be used in analyzing geophysical processes in this tight-sandstone environment.

\section{ACKNOWLEDGMENTS}

The authors would like to acknowledge the support of the Gas Research Institute and the U.S. Department of Energy in the funding and management of this project. Additional thanks go to Rich Peterson at Branagan \& Associates, Terry Steinfort at Sandia Natl. Labs, and Gary Holzhausen at Applied Geomechanics, Inc.

\section{REFERENCES}

Albright, J.N. and Pearson, C.F. (1982). Acoustic emissions as a tool for hydraulic fracture location: experience at the Fenton Hill hot dry rock site. SPE Journal, 22, 523-530.

Branagan, P.T., Peterson, R., Warpinski, N.R. and Wright, T.B. (1996). The characterization of remotely intersected set of hydraulic fractures: results of intersection well no. 1: GRI/DOE Multi-Site project. SPE 36452, SPE Annual Technical Conference \& Exhibition, Denver, CO, $\Delta, 351-362$.

Branagan, P.T., Warpinski, N.R., Engler, B.P. and Wilmer, R. (1996). Measuring hydraulic fracture-induced deformation of reservoir and adjacent rocks employing a deeply buried inclinometer array: GRI/DOE MultiSite project. SPE 36451, SPE Annual Technical Conference \& Exhibition, Denver, CO, $\Delta, 337-350$. Davis, P.M. (1983). Surface deformation associated with a dipping hydrofracture. Journal of Geophysical Research, 88:B7, 5826.

England, A.H. and Green, A.E. (1963). Some two-dimensional punch and crack problems in classical elasticity. Proceedings, Cambridge Philosophical Society, 59, 489-500.

Gidley, J.L., Holditch,S.A., Nierode, D.E. and Veatch, R.W., Editors (1989). Recent Advances in Hydraulic Fracturing, SPE Monograph Volume 12, Society of Petroleum Engineers, Richardson, TX.

Green, A.E. and Sneddon, I.N. (1950) The distribution of stress in the neighbourhood of a flat elliptical crack in an elastic solid. Proceedings Cambridge Philosophical Society, 46, 159-163.

Hart, C. M., Engi, D., Fleming, R. P. and Morris, H. E. (1984). Fracture diagnostics results for the multiwell experiment's paludal zone stimulation. Paper SPE 12852, SPE/DOE Unconventional Gas Recovery Symposium, Pittsburgh, PA, 221-228.

Peterson, R.E., Wolhart, S.L., Frohne, K.-H., Warpinski, N.R., Branagan, P.T. and Wright, T.B. (1996). Fracture diagnostics research at the GRI/DOE Multi-Site project: overview of the concept and results. SPE 36449, 1996 SPE Annual Tech. Conf. and Exhibition, Denver, CO, $\Delta, 315-326$.

Sneddon, I.N. (1946). The distribution of stress in the neighborhood of a crack in an elastic solid.

Proceedings, Royal Society of London, 187, 229-260.

Sleefe, G.E., Warpinski, N.R. and Engler, B.P. (1995). The use of broadband microseisms for hydraulic fracture mapping. SPE Formation Evaluation, 47, 233-239.

Warpinski, N.R., Moschovidis, Z.A., Parker, C.D. and Abou-Sayed, I.S. (1994). Comparison study of hydraulic fracturing models test case: GRI staged field experiment 3. SPE Production \& Facilities, 46, 7-16. Warpinski, N.R., Wright, T.B., Uhl, J.E., Engler, B.P., Drozda, P.M. and Peterson, R.E. (1996). Microseismic monitoring of the b-sand hydraulic fracture experiment at the DOE/GRI Multi-Site project. SPE 36450, 1996 SPE Annual Technical Conference \& Exhibition, Denver, CO, $\triangle, 327-335$.

Warpinski, N.R. (1994). Interpretation of hydraulic fracture mapping experiments. Paper SPE 27985, Tulsa Centennial Petroleum Engineering Symposium, Tulsa, OK, 291-300.

Warpinski, N.R., Engler, B.P., Young, C.J., Peterson, R., Branagan, P.T. and Fix, J.E. (1995). Microseismic mapping of hydraulic fractures using mult-level wireline receivers. Paper SPE 30507, SPE Annual Technical Conference and Exhibition, Dallas, TX, $\Delta, 579-589$.

Wright, C.A. and Conant, R.A. (1995). Hydraulic fracture reorientation in primary and secondary recovery from low permeability reservoirs. SPE 30484, SPE Annual Technical Conference \& Exhibition, Dallas, TX, $\Pi, 357-369$. 